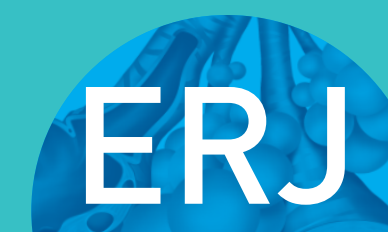

open research
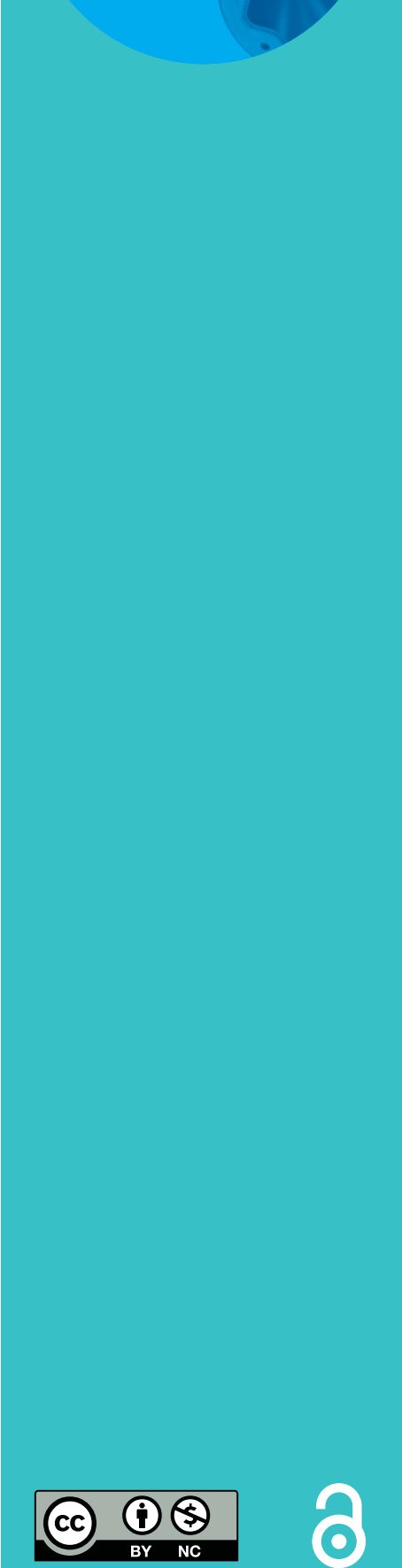

\section{Maximal aerobic capacity in ageing subjects: actual measurements versus predicted values}

\author{
Cristina Pistea, Evelyne Lonsdorfer, Stéphane Doutreleau, Monique Oswald, \\ Irina Enache and Anne Charloux
}

Affiliation: Service de Physiologie et d'Explorations Fonctionnelles, Pôle de Pathologie Thoracique, Hôpitaux Universitaires de Strasbourg et Equipe d'Accueil 3072, Fédération de Médecine Translationnelle de Strasbourg, Université de Strasbourg, Strasbourg, France.

Correspondence: Anne Charloux, Service de Physiologie et d'Explorations Fonctionnelles, Nouvel Hôpital Civil, Hôpitaux Universitaires de Strasbourg, BP 426, 1 Place de l'Hôpital, 67091 Strasbourg Cedex France. E-mail: Anne.Charloux@achru-strasbourg.fr

ABSTRACT We evaluated the impact of selection of reference values on the categorisation of measured maximal oxygen consumption $\left(V^{\prime} \mathrm{O}_{2}\right.$ peak $)$ as "normal" or "abnormal" in an ageing population.

We compared measured $V^{\prime} \mathrm{O}_{2}$ peak with predicted values and the lower limit of normal (LLN) calculated with five equations. 99 (58 males and 41 females) disease-free subjects aged $\geqslant 70$ years completed an incremental maximal exercise test on a cycle ergometer.

Mean $V^{\prime} \mathrm{O}_{2}$ peak was $1.88 \mathrm{~L} \cdot \mathrm{min}^{-1}$ in men and $1.26 \mathrm{~L} \cdot \mathrm{min}^{-1}$ in women. $V^{\prime} \mathrm{O}_{2}$ peak ranged from $89 \%$ to $108 \%$ of predicted in men, and from $88 \%$ to $164 \%$ of predicted in women, depending on the reference equation used. The proportion of subjects below the LLN ranged from $5 \%$ to $14 \%$ in men and $0-22 \%$ in women, depending on the reference equation. The LLN was lacking in one study, and was unsuitable for women in another. Most LLNs ranged between $53 \%$ and $73 \%$ of predicted. Therefore, choosing an $80 \%$ cut-off leads to overestimation of the proportion of "abnormal" subjects.

To conclude, the proportion of subjects aged $\geqslant 70$ years with a "low" $V^{\prime} \mathrm{O}_{2}$ peak differs markedly according to the chosen reference equations. In clinical practice, it is still relevant to test a sample of healthy volunteers and select the reference equations that better characterise this sample.

@ERSpublications

As $V^{\prime} \mathrm{O}_{2}$ peak \% pred differs markedly with the reference value, reference equation choice is critical in the elderly http://ow.ly/YsXHD

Received: Sept 152015 | Accepted after revision: Feb 052016

Conflict of interest: Disclosures can be found alongside the online version of this article at openres.ersjournals.com

Copyright $\odot$ ERS 2016. This article is open access and distributed under the terms of the Creative Commons Attribution Non-Commercial Licence 4.0. 


\section{Introduction}

Measuring the maximal oxygen consumption $\left(V^{\prime} \mathrm{O}_{2} \max \right)$ during an incremental test provides relevant information on risk or prognosis of various diseases [1-3]. In addition, precisely assessing the subject's functional capacity allows tailoring of rehabilitation programmes. Such programmes are increasingly offered to ageing subjects $[4,5]$. Proper interpretation of the measured $V^{\prime} \mathrm{O}_{2}$ max requires its comparison with well-selected reference values. The use of some equations has been recommended in international guidelines $[6,7]$. However, most of these equations have been elaborated from small series, and include subjects under the age of 71 [8] or 74 years [9-11]. As a result, these validated reference equations provide predicted values for the elderly that are largely extrapolated from the models established by these authors. Other authors provide specific reference values for healthy ageing men and women [12-14], but only one study [12] has been referenced in guidelines [6]. In addition, earlier reference values published in the 1970s and 1980s [8-10] may no longer be adapted to the current ageing population, which, with respect to previous ones, has a different history and lifestyle, and increased longevity. Consequently, it may be justified to use reference values derived from studies that include contemporary population samples. In view of this, recent studies have been published [15-17]. These well-designed studies are population-based and provide predicted $V^{\prime} \mathrm{O}_{2}$ max values over a wide range of ages.

Taking into account the disparities between the studies discussed above, we hypothesised that predicted $V^{\prime} \mathrm{O}_{2} \max$ values for older people may vary significantly according to the selected reference equation. Therefore, to evaluate the impact of selection of reference values on the categorisation of $V^{\prime} \mathrm{O}_{2}$ max as "normal" or "abnormal", we compared the measured maximal oxygen consumption $\left(V^{\prime} \mathrm{O}_{2}\right.$ peak $)$ on a cycle ergometer in 99 healthy Caucasian subjects aged $\geqslant 70$ years with the predicted $V^{\prime} \mathrm{O}_{2} \max$ provided by five different studies. We calculated the differences between the measured $V^{\prime} \mathrm{O}_{2}$ peak and the predicted $V^{\prime} \mathrm{O}_{2}$ max, and also examined relationships between the measured $V^{\prime} \mathrm{O}_{2}$ peak and the lower limit of normal (LLN).

\section{Materials and methods}

\section{Design, subjects and exercise tests}

This study was approved by the Ethics Committees of the Medical, Dentistry and Pharmacy Faculties (University of Strasbourg, Strasbourg, France) and of the Strasbourg Hospital, Strasbourg, France (administration number: 2013/26). Table 1 provides the reference equations/predicted values and LLNs we used in this study. To compare predicted $V^{\prime} \mathrm{O}_{2}$ max values to measured $V^{\prime} \mathrm{O}_{2}$ peak, 99 healthy subjects referred by their general practitioner before participating in an exercising programme offered by their medical insurance or before joining sports clubs or associations between January 2009 and December 2012 were included. All subjects lived in the department of Bas-Rhin, in Alsace, France. Subjects were free of chronic diseases, but mild and controlled hypertension or dyslipidaemia, tobacco consumption or overweight were not exclusion criteria [8, 10-13]. An activity questionnaire (adapted from [18]) was filled out by each participant. A maximal symptom-limited incremental exercise test was performed using an electrically braked cycle ergometer (Ergoselect 200P; Ergoline, Bitz, Germany) following recommendations [6]. Oxygen uptake $\left(V^{\prime} \mathrm{O}_{2}\right)$ was measured using a breath-by-breath method (Ultima Cardio2; MedGraphics, Milan, Italy). We measured $V^{\prime} \mathrm{O}_{2}$ peak since, as expected, a $V^{\prime} \mathrm{O}_{2}$ plateau was not achieved by all subjects [12, 13]. The exercise test was considered maximal if it was symptom-limited with overall fatigue (Borg scale rating $9-10$, on a $0-10$ scale) and inability to maintain the pedalling rate $>60 \mathrm{rpm}$ [7].

\section{Data analysis}

Results are expressed as mean \pm SD or proportions. Predicted $V^{\prime} \mathrm{O}_{2} \max$ was calculated using five different sets of reference equations, by Wasserman et al. [11], Jones et al. [8], BLACKIE et al. [12], HakOla et al. [13] and Косн et al. [17]. To compare measured $V^{\prime} \mathrm{O}_{2}$ peak with predicted $V^{\prime} \mathrm{O}_{2} \max$, we calculated the mean difference ( $V^{\prime} \mathrm{O}_{2}$ peak minus predicted $V^{\prime} \mathrm{O}_{2} \max$ ), and the $90 \%$ confidence interval of the differences for each predicted equation. Only one author provided equations to calculate the fifth percentile, used as LLN [17]. For the other studies, we determined LLN as mean-2SD. Since no standard deviation was available in the publication by WASSERMAN et al. [11], no LLN could be calculated. The percentage of subjects with values below the LLN of $V^{\prime} \mathrm{O}_{2} \max$ was calculated for each equation. $V^{\prime} \mathrm{O}_{2}$ peak was compared according to the grade of physical activity using a two-way ANOVA.

\section{Results}

Table 1 provides the reference equations we used [8,11-13, 17], as well as the characteristics of the population samples selected by the authors to elaborate these equations. Predicted $V^{\prime} \mathrm{O}_{2} \max$ and LLN $\left(\mathrm{L} \cdot \mathrm{min}^{-1}\right.$ ) have been calculated for an illustrative individual (72 years-old; man: $80 \mathrm{~kg}$ and $172 \mathrm{~cm}$; woman: $67 \mathrm{~kg}$ and $160 \mathrm{~cm}$ ) using each equation.

The characteristics of our subjects are presented in table 2. 58 men and 41 women were included. All subjects were Caucasian, and had normal spirometry and echocardiography. $83 \%$ of men and $63 \%$ of 
TABLE 1 Equations used for calculation of predicted maximal oxygen consumption $\left(\mathrm{V}^{\prime} \mathrm{O}_{2} \max \right)$

\begin{tabular}{|c|c|c|}
\hline First author [ref.], year & Characteristics of the population samples & Prediction equations for $V^{\prime} \mathrm{O}_{2} \max \#$ \\
\hline WASSERMAN [11], 1999 & $\begin{array}{l}\text { The published equations were modified from: } \\
\text { HANSEN et al. [10] } \\
77 \text { males, 34-74 years } \\
\text { Asbestos exposed workers with normal } \\
\text { cardiorespiratory function, California, USA } \\
\text { BRUCE et al. [9] } \\
138 \text { males, } 157 \text { females, 29-73 years } \\
\text { General population, Washington, USA }\end{array}$ & 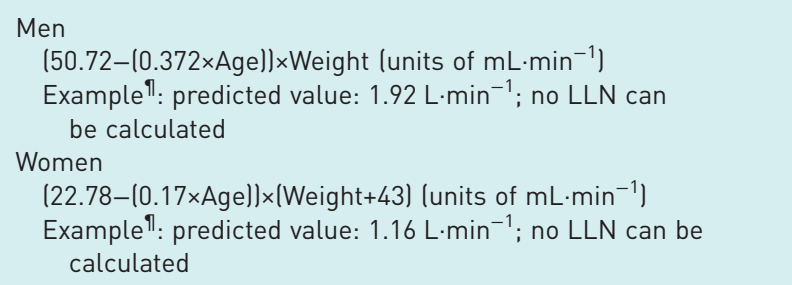 \\
\hline JoNes [8], 1985 & $\begin{array}{l}50 \text { males, } 50 \text { females, } 15-71 \text { years } \\
\text { Subjects recruited by advertising from the } \\
\text { local university and general population, } \\
\text { Ontario, Canada }\end{array}$ & 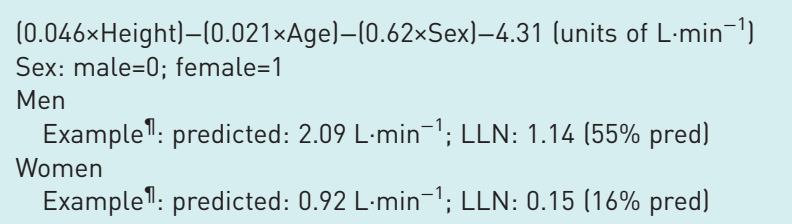 \\
\hline BLACKIE [12], 1989 & $\begin{array}{l}81 \text { males, } 47 \text { females, } 55-80 \text { years } \\
\text { Subjects recruited locally by advertising } \\
\text { from hospital and community centres, } \\
\text { British Columbia, Canada }\end{array}$ & 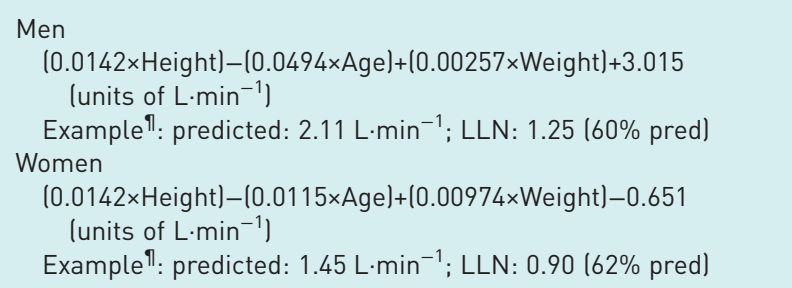 \\
\hline Косн [17], 2009 & $\begin{array}{l}\text { Disease-free subjects, } 253 \text { males, } 281 \text { females, } \\
25-80 \text { years } \\
\text { Representative sample selected from the } \\
\text { population registration offices in Pomerania, } \\
\text { Germany }\end{array}$ & 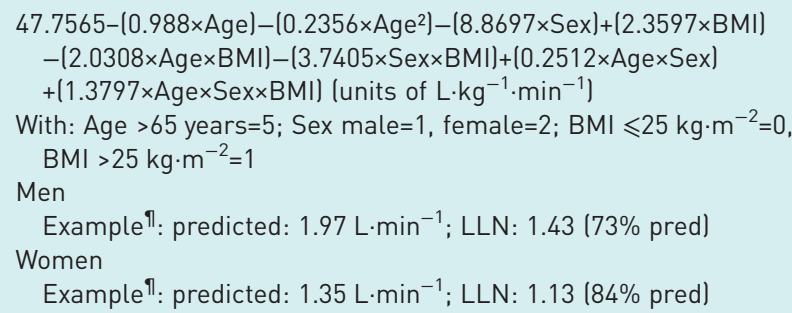 \\
\hline HAKOLA [13], 2011 & $\begin{array}{l}\text { Nondiseased subjects, } 117 \text { males, } 112 \text { females, } \\
57-78 \text { years } \\
\text { Subjects randomly selected from the town } \\
\text { of Kuopio, Finland }\end{array}$ & 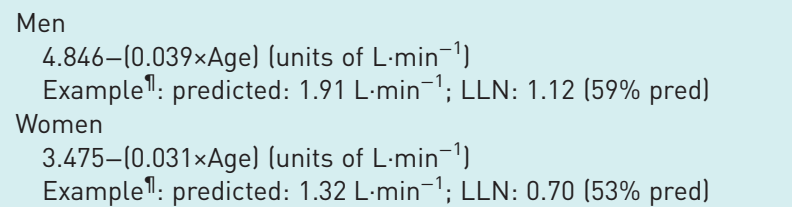 \\
\hline
\end{tabular}

Exercise tests were performed using cycle ergometers. LLN: lower limit of normal; BMI: body mass index. \#: for all equations, age is in years, height in $\mathrm{cm}$ and weight in $\mathrm{kg}$; " : Predicted $V^{\prime} \mathrm{O}_{2} \max$ and LLN (L· $\left.\mathrm{min}^{-1}\right)$ have been calculated for an illustrative individual (72 years-old; male: $80 \mathrm{~kg}$ and $172 \mathrm{~cm}$; female: $67 \mathrm{~kg}$ and $160 \mathrm{~cm}$ ).

women had a body mass index $>25 \mathrm{~kg} \cdot \mathrm{m}^{-2}$. $63 \%$ of males and $22 \%$ of females were current or former-smokers. Most subjects (53\% of men and 66\% of women) reported moderate physical activity, while 19 males and females reported intense physical activity. These physical activities included heavy gardening and yard work, yoga and gymnastic/fitness, walking/hiking, cycling, swimming, and cross-country skiing. The 19 (19\%) subjects who reported intense physical activity practiced at least two sports. The more intense the activity level the higher the $V^{\prime} \mathrm{O}_{2}$ peak $(\mathrm{p}<0.05) . V^{\prime} \mathrm{O}_{2}$ peak was $23.05 \pm 5.47 \mathrm{~mL} \cdot \mathrm{min}^{-1} \cdot \mathrm{kg}^{-1}$ in men and $18.94 \pm 4 \mathrm{~mL} \cdot \mathrm{min}^{-1} \cdot \mathrm{kg}^{-1}$ in women, and maximal workload was $127 \pm 37 \mathrm{~W}\left(1.57 \mathrm{~W} \cdot \mathrm{kg}^{-1}\right)$ in men and $84 \pm 18 \mathrm{~W}\left(1.27 \mathrm{~W} \cdot \mathrm{kg}^{-1}\right)$ in women. Oxygen saturation monitored by pulse oximetry remained stable throughout the exercise test. Maximal heart rate, ventilation, respiratory exchange ratio and respiratory equivalents were not different in men and women.

Table 3 provides means and $90 \%$ confidence intervals of the differences between measured and predicted $V^{\prime} \mathrm{O}_{2}$ values. Figure 1 illustrates the measured $V^{\prime} \mathrm{O}_{2}$ peak in our subjects and the normal values calculated with the five equations for an $80 \mathrm{~kg}$ and $172 \mathrm{~cm}$ man, and a $67 \mathrm{~kg}$ and $160 \mathrm{~cm}$ woman. Table 3 shows that mean $V^{\prime} \mathrm{O}_{2}$ peak ranged from $89 \%$ and $108 \%$ of predicted, and mean (measured-predicted) differences ranged from $-250 \mathrm{~mL}$ to $+150 \mathrm{~mL}$ in men, according to the reference values used. In women, mean 


\section{TABLE 2 Subjects' characteristics, spirometry and exercise test results}

Men

Subjects $n$

Age years

Weight kg

Height $\mathrm{cm}$

Body mass index $\mathrm{kg} \cdot \mathrm{m}^{-2}$

Current smokers

Former smokers

Intense physical activity

Moderate physical activity

Sedentary

FVC L

FVC \% predicted

FEV 1 L

FEV $1 \%$ pred

FEV $1 /$ FVC \%

Oxygen uptake at rest L.min ${ }^{-1}$

Heart rate at rest beats $\mathrm{min}^{-1}$

Ventilation at rest $L$

$\mathrm{mL} \cdot \mathrm{min}^{-1} \cdot \mathrm{kg}^{-1}$

Maximal workload W

Maximal heart rate beats $\cdot \mathrm{min}^{-1}$

$\%$ pred $^{\#}$

Maximal ventilation $\mathrm{L}$

$\%$ pred $^{\#}$

Maximal $V^{\prime} \mathrm{E} / V^{\prime} \mathrm{CO}_{2}$

Maximal $V^{\prime} \mathrm{E} / V^{\prime} \mathrm{O}_{2}$

Maximal respiratory exchange ratio

Men

Maximal oxygen uptake L· $\min ^{-1}$

Women

$\begin{array}{cc}58 & 41 \\ 73.6 \pm 4.0 & 73.2 \pm 2.7 \\ 81.3 \pm 13.3 & 67.7 \pm 11.5 \\ 172.2 \pm 0.1 & 159.5 \pm 0.1 \\ 28.0 \pm 3.6 & 26.2 \pm 3.6 \\ 5(8.6) & 0(0) \\ 32(55.0) & 9(21.9) \\ 13(22.4) & 6(14.6) \\ 31(53.4) & 27(65.8) \\ 14(24.2) & 8(19.6) \\ 3.7 \pm 0.7 & 2.8 \pm 0.6 \\ 101.7 \pm 20.1 & 122.8 \pm 25.4 \\ 2.7 \pm 0.6 & 2.2 \pm 0.4 \\ 99.6 \pm 22.8 & 117.1 \pm 21.6 \\ 74.1 \pm 8.9 & 78.7 \pm 6.3 \\ 0.30 \pm 0.07 & 0.23 \pm 0.06 \\ 76 \pm 12 & 77 \pm 13 \\ 11.52 \pm 2.61 & 8.42 \pm 1.64 \\ 1.88 \pm 0.41 & 1.26 \pm 0.24 \\ 23.05 \pm 5.47 & 18.94 \pm 4.00 \\ 127.33 \pm 36.66 & 84.20 \pm 18.29 \\ 142 \pm 21 & 137 \pm 18 \\ 87.2 \pm 13.0 & 85.8 \pm 10.6 \\ 72.77 \pm 18.31 & 49.50 \pm 13.22 \\ 77.6 \pm 17.4 & 68.0 \pm 16.7 \\ 34.19 \pm 4.63 & 34.83 \pm 5.66 \\ 38.38 \pm 7.37 & 39.40 \pm 6.91 \\ 1.14 \pm 0.10 & 1.15 \pm 0.07\end{array}$

Data are presented as mean \pm SD or $\mathrm{n}(\%)$, unless otherwise stated. The exercise test was performed on an electrically-braked cycle ergometer. FVC: forced vital capacity; FEV1: forced expiratory volume in $1 \mathrm{~s} ; V^{\prime} \mathrm{E}$ : minute ventilation; $V^{\prime} \mathrm{CO}_{2}$ : carbon dioxide output; $V^{\prime} \mathrm{O}_{2}$ : oxygen uptake. ${ }^{\#}$ : predicted maximal ventilation was calculated as the subject's FEV1×35; predicted maximal heart rate was calculated as $210-0.65 \times$ (age) [7].

$V^{\prime} \mathrm{O}_{2}$ peak ranged from $88 \%$ and $164 \%$ of predicted, and mean (measured-predicted) differences ranged from $-190 \mathrm{~mL}$ to $+350 \mathrm{~mL}$. The proportion of men below the LLN ranged from $5 \%$ to $14 \%$, and the proportion of women ranged from $0 \%$ to $22 \%$. The dispersion of the (measured-predicted) differences (reflected by the bounds of the $90 \%$ CI; table 2) was wider using the equation of JonEs et al. [8] for women, because of the huge dispersion of the predicted values using this equation $\left(0.14-1.54 \mathrm{~L} \cdot \mathrm{min}^{-1}\right)$. In addition, these predicted values for women were very low.

\section{Discussion}

In this study, we expressed the measured $V^{\prime} \mathrm{O}_{2}$ peak of 99 disease-free, $\geqslant 70$ year-old subjects as the percentage of the reference values calculated using five different reference equations. Mean $V^{\prime} \mathrm{O}_{2}$ peak ranged from $89 \%$ to $108 \%$ of predicted in men, and from $88 \%$ to $164 \%$ in women, depending on the reference equation used. In addition, we found that the proportion of subjects showing $V^{\prime} \mathrm{O}_{2}$ peak below the LLN ranged from $5 \%$ to $14 \%$ in men and $0 \%$ to $22 \%$ in women, depending on the reference equation.

This study has three main limitations. First, the maximal exercise tests were performed on a cycle ergometer. Thus, the results cannot be extrapolated to $V^{\prime} \mathrm{O}_{2} \max$ measured on a treadmill. Secondly, not all available reference equations were tested. Thirdly, the characteristics of our sample subjects can be a subject of discussion.

Numerous reference equations or normal values have been published for $V^{\prime} \mathrm{O}_{2} \max$, which do or do not include older people. We did not perform a comprehensive review of these equations, but aimed to show that $V^{\prime} \mathrm{O}_{2}$ peak expressed as per cent predicted as well as proportions of subjects with "low" $V^{\prime} \mathrm{O}_{2}$ peak differ markedly according to the equation used. Among the five studies we selected, the studies by Jones et al. [8], WASSERMAN et al. [11] and BLACKIE et al. [12] were regarded by the 1997 European Respiratory Society task force [6] to fulfil the minimum requirements to be used in the clinical setting. The 2003 American Thoracic Society/American College of Chest Physicians committee [7] concluded that, even if not optimal, the 


\section{TABLE 3 Comparison of measured maximal oxygen consumption $\left(\mathrm{V}^{\prime} \mathrm{O}_{2}\right.$ peak $)$ versus predicted maximal oxygen consumption $\left(\mathrm{V}^{\prime} \mathrm{O}_{2} \mathrm{max}\right)$ according to prediction equations from five studies}

\begin{tabular}{|c|c|c|c|c|}
\hline Sample & $\begin{array}{l}\text { Prediction } \\
\text { equation }\end{array}$ & $\begin{array}{l}V^{\prime} \mathrm{o}_{2} \text { peak } \% \\
\text { predicted }\end{array}$ & $\begin{array}{l}V^{\prime} \mathrm{O}_{2} \text { peak minus } \\
V^{\prime} \mathrm{O}_{2} \max \mathrm{L} \cdot \mathrm{min}^{-1}\end{array}$ & $\begin{array}{l}\text { Subjects with } \\
V^{\prime} 0_{2} \text { peak }<L L N^{\#}\end{array}$ \\
\hline \multirow{5}{*}{$\begin{array}{l}58 \text { disease-free men, } \\
>70 \text { years old }\end{array}$} & WASSERMAN et al. [11] & $108 \pm 23$ & $0.15(-0.50-0.79)$ & \\
\hline & JonES et al. [8] & $92 \pm 20$ & $-0.18(-0.87-0.52)$ & $3(5)$ \\
\hline & BLACKIE et al. [12] & $93 \pm 21$ & $-0.16(-0.85-0.54)$ & 4 (7) \\
\hline & KocH et al. [17] & $89 \pm 20$ & $-0.25(-0.95-0.45)$ & $8(14)$ \\
\hline & HAKOLA et al. [13] & $103 \pm 24$ & $0.04(-0.65-0.74)$ & $3(5)$ \\
\hline \multirow{5}{*}{$\begin{array}{l}41 \text { disease-free women, } \\
>70 \text { years old }\end{array}$} & WASSERMAN et al. [11] & $117 \pm 20$ & $0.19(-0.17-0.55)$ & \\
\hline & JonEs et al. [8] & $164 \pm 103$ & $0.35(-0.19-0.88)$ & $0(0)$ \\
\hline & BLACKIE et al. [12] & $88 \pm 16$ & $-0.19(-0.59-0.22)$ & $0(0)$ \\
\hline & Косн et al. [17] & $90 \pm 17$ & $-0.15(-0.59-0.28)$ & $9(22)$ \\
\hline & HaKoLA et al. [13] & $98 \pm 18$ & $-0.03(-0.41-0.35)$ & $0(0)$ \\
\hline
\end{tabular}

reference values of JONEs et al. [8] and WASSERMAn et al. [11] should continue to be used clinically. We tested these equations on subjects aged $\geqslant 70$ years, whose demand for exercise testing and rehabilitation is growing. However, the validity of the predicted $V^{\prime} \mathrm{O}_{2} \max$ values may be questioned for this age group. Indeed, the oldest subjects in the studies by JONES et al. [8] and WASSERMAN et al. [11] were only 71 and 74 years old, respectively. As a result, predicted values for people aged $>70$ years people are mainly extrapolated from their linear models. Since the $V^{\prime} \mathrm{O}_{2}$ max/age relationship has been found to be nonlinear in some studies $[16,17,19]$ using these equations may lead to improper reference values. We also studied two equations derived from "ageing" populations. The studies by HaKola et al. [13] and Blackie et al. [12] included 15 and 36 subjects aged $>70$ years, which is not that high. We eventually selected the equation from КосH et al. [17], elaborated from one of the largest published population-based series. It included 25 subjects aged $>65$ years [17]. When using this equation, the predicted $V^{\prime} \mathrm{O}_{2} \max$ for a given subject with stable weight and height doesn't vary beyond age 65 years, since age is not a continuous variable. It is interesting to note that WASSERMAN et al. [11] and $\mathrm{Koch}$ et al. [17] took into account the effect of obesity or overweight on $V^{\prime} \mathrm{O}_{2}$ max, whereas height and weight were not included in the equation used by HaKola et al. [13].

The selection of our subjects needs to be further discussed. First, a lack of disease or risk factors beyond the age of 70 years is uncommon. Our subjects were free of chronic diseases and had normal echocardiography and spirometry. However, we included, as did other authors, subjects who strictly speaking could not to be considered as "healthy". Smokers or ex-smokers [12, 13, 15, 17] or overweight subjects [11, 13, 15, 17] were not excluded from most studies. КocH et al. [17] showed that arterial hypertension and/or beta blocker treatment did not have a significant influence on $V^{\prime} \mathrm{O}_{2} \max$, and these were not regarded as exclusion criteria. We recorded normal end-exercise cardiorespiratory values for this age group [20], in both men and women. Compared with younger subjects, it has been demonstrated that maximal $V^{\prime} \mathrm{O}_{2}$, carbon dioxide output $\left(V^{\prime} \mathrm{CO}_{2}\right)$, heart rate, ventilation and end-tidal carbon dioxide tension
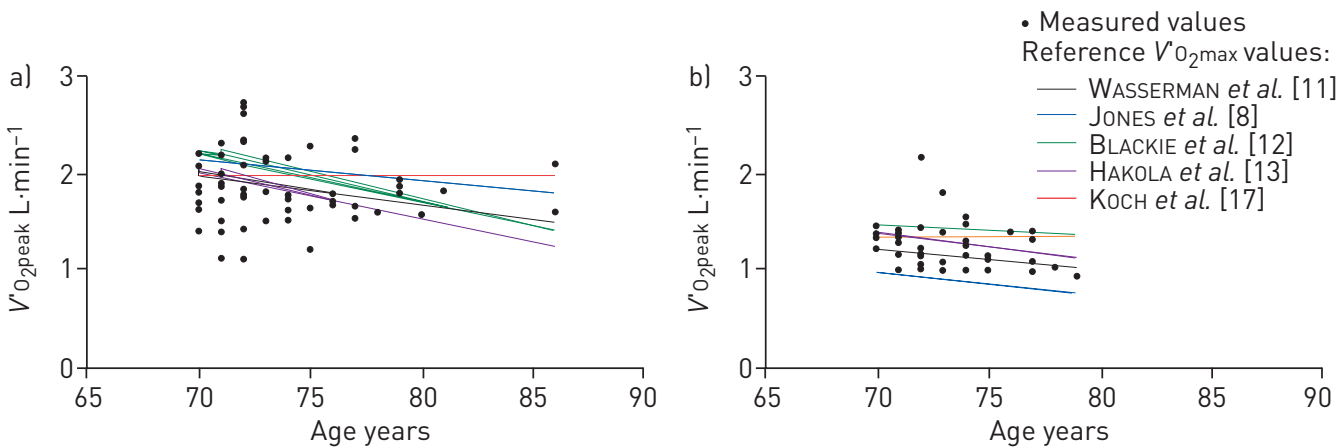

FIGURE 1 Measured maximal oxygen consumption $\left(\mathrm{V}^{\prime} \mathrm{O}_{2}\right.$ peak $)$ in a) 58 men and b) 41 women, aged $>70$ years and free of chronic diseases. Predicted maximal oxygen consumption $\left(\mathrm{V}^{\prime} \mathrm{O}_{2} \mathrm{max}\right)$ reference values and their changes with age were calculated using reference equations by WASSERMAN et al. [11], JonES et al. [8], BLACKIE et al. [12], HAKOLA et al. [13] and $\mathrm{KocH}$ et al. [17] for an illustrative individual (male: $80 \mathrm{~kg}$ and $172 \mathrm{~cm}$; female: $67 \mathrm{~kg}$ and $160 \mathrm{~cm}$; mean heights and weights in our study). 
significantly decline with age, whereas minute ventilation $\left(V^{\prime} \mathrm{E}\right) / V^{\prime} \mathrm{CO}_{2}$ and $V^{\prime} \mathrm{E} / V^{\prime} \mathrm{O}_{2}$ slightly increase, and respiratory exchange ratio and end-tidal oxygen tension do not change significantly [20]. Secondly, our selection of subjects was inherently biased as no formal random selection from a large population was used. Our subjects were referred before joining sports clubs or exercise programmes, lived in Alsace, and were part of our routine clinical practice. Thirdly, comparison of our maximal $V^{\prime} \mathrm{O}_{2}$, ventilation and heart rate values to recently published values $[15,16]$ may suggest that the efforts of some of our subjects may have been submaximal. These observations are of course of relevance. However, our purpose was not to provide normal values for French older people, but to use $V^{\prime} \mathrm{O}_{2}$ peak results obtained routinely, in "healthy" subjects, to compare actual to predicted $V^{\prime} \mathrm{O}_{2}$ max.

This study led to some findings that could guide the selection of reference equations for ageing people. In men, predicted $V^{\prime} \mathrm{O}_{2} \max$ were not very different from one another and fitted with our subjects' measured $V^{\prime} \mathrm{O}_{2}$ peak, whatever the reference equation. In women, predicted values were more widely distributed than in men. The studies by JONEs et al. [8] and WASSERMAN et al. [11] provided the lowest predicted $V^{\prime} \mathrm{O}_{2}$ max values. In our opinion, the equation of Jones et al. [8] provides unsuitable predicted $V^{\prime} \mathrm{O}_{2} \max$ for ageing women, as our mean $V^{\prime} \mathrm{O}_{2}$ peak value corresponded to $164 \%$ of predicted. Predicted values for women calculated using the equations of BLACKIE et al. [11], КосH et al. [17] and HAKOLA et al. [13] were reasonably close to each other and fit our population. Interestingly, predicted $V^{\prime} \mathrm{O}_{2} \max$ values provided by two recent studies are very high compared with those we selected $[15,16]$. For instance, the predicted $V^{\prime} \mathrm{O}_{2}$ max is $2.81 \mathrm{~L} \cdot \mathrm{min}^{-1}$ for men aged $>70$ years and $1.85 \mathrm{~L} \cdot \mathrm{min}^{-1}$ for women aged $>70$ years in the study by LoE et al. [16]. The subjects were tested on a treadmill and not on a cycle, and the use of a treadmill usually results in $10-15 \%$ higher $V^{\prime} \mathrm{O}_{2} \max$ [21]. However, after application of the corrective factor, these predicted $V^{\prime} \mathrm{O}_{2} \max$ remain higher than the previous ones, raising the question of a secular trend.

The main finding of this study is that LLN differed a lot from one study to another. As a result, depending on the selected reference equation, $5-14 \%$ of men and $0-22 \%$ of women were categorised as "abnormal". We showed that the LLN of JonEs et al. [8] for women were very low and seem unsuitable for clinical practice, whatever the studied female population. The data of WASSERMAN et al. [11] did not allow calculation of the LLN. In such a case, a $<80 \%$ of predicted cut-off is frequently used in practice to define "abnormality". As shown in table 1, we found that after excluding the extremes, LLN ranged between 53\% and $73 \%$ of the predicted value in both men and women. This demonstrates that the choice of an $80 \%$ cut-off leads to overestimate the proportion of "abnormal" older subjects and should not be used. Again, we found that the LLN was more widely distributed in women (16-84\% of predicted) than in men (55-73\% of predicted) (table 1). Altogether, these results provide evidence that LLN needs to be well characterised in published studies and applied in clinical practice. In addition, the wide range of LLN recorded in the literature should prompt additional studies in women.

The heterogeneity of the reference values we examined can be partly explained by technical reasons (e.g. exercise protocol and type of gas exchange analyser) and partly by methodological issues (e.g. sample size, criteria for subject selection and maximal effort, and treatment of data). However, the main factor is probably the characteristics of the reference population from which the sample is drawn. Obviously, reference equations cannot be used irrespective of the population from which a subject comes. Guidelines recommend testing a sample of healthy volunteers and selecting the reference values that better characterise this sample [7], emphasising the importance of matching reference values to the population base. Based on the current analysis, this recommendation still appears worthy of consideration.

To conclude, this study stresses the importance of the selection of $V^{\prime} \mathrm{O}_{2}$ max reference equations, especially for older subjects, and offers clinicians some information to guide their choice. However, an alternative approach to the difficult issue of subjects' categorisation as "normal" or not would be to evaluate mortality risk or prognosis associated with $V^{\prime} \mathrm{O}_{2}$ max results, which would be particularly relevant in ageing subjects. Indeed, the question of how healthy older people should be to be regarded as "normal" today is a matter of debate.

\section{References}

$1 \quad$ Kappagoda T, Amsterdam EA. Exercise and heart failure in the elderly. Heart Fail Rev 2012; 17: 635-662.

2 Liu R, Sui X, Laditka JN, et al. Cardiorespiratory fitness as a predictor of dementia mortality in men and women. Med Sci Sports Exerc 2012; 44: 253-259.

3 Faselis C, Doumas M, Pittaras A, et al. Exercise capacity and all-cause mortality in male veterans with hypertension aged $\geqslant 70$ years. Hypertension 2014; 64: 30-35.

4 Corhay JL, Nguyen D, Duysinx B, et al. Should we exclude elderly patients with chronic obstructive pulmonary disease from a long-time ambulatory pulmonary rehabilitation programme? J Rehabil Med 2012; 44: 466-472.

5 Vogel T, Leprêtre PM, Brechat PH, et al. Effects of a short-term personalized Intermittent Work Exercise Program (IWEP) on maximal cardio-respiratory function and endurance parameters among healthy young and older seniors. J Nutr Health Aging 2011; 15: 905-911.

6 ERS Task Force on Standardization of Clinical Exercise Testing. Clinical exercise testing with reference to lung diseases: indications, standardization and interpretation strategies. Eur Respir J 1997; 10: 2662-2689. 
7 American Thoracic Society, American College of Chest Physicians. ATS/ACCP Statement on cardiopulmonary exercise testing. Am J Respir Crit Care Med 2003; 167: 211-277.

8 Jones NL, Makrides L, Hitchcock C, et al. Normal standards for an incremental progressive cycle ergometer test. Am Rev Respir Dis 1985; 131: 700-708.

9 Bruce RA, Kusumi F, Hosmer D. Maximal oxygen intake and nomographic assessment of functional aerobic impairment in cardiovascular disease. Am Heart J 1973; 85: 546-562.

10 Hansen JE, Sue DY, Wasserman K. Predicted values for clinical exercise testing. Am Rev Respir Dis 1984; 129: S49-S55.

11 Wasserman K, Hansen JE, Sue DY, et al. Principles of exercise testing and interpretation: including pathophysiology and clinical applications. 3rd Edn. Lippincott Williams \& Wilkins, 1999.

12 Blackie SP, Fairbarn MS, McElvaney GN, et al. Prediction of maximal oxygen uptake and power during cycle ergometry in subjects older than 55 years of age. Am Rev Respir Dis 1989; 139: 1424-1429.

13 Hakola L, Komulainen P, Hassinen M, et al. Cardiorespiratory fitness in aging men and women: the DR's EXTRA study. Scand J Med Sci Sports 2011; 21: 679-687.

14 Paterson DH, Cunningham DA, Koval JJ, et al. Aerobic fitness in a population of independently living men and women aged 55-86 years. Med Sci Sports Exerc 1999; 31: 1813-1820.

15 Edvardsen E, Scient C, Hansen $\mathrm{BH}$, et al. Reference values for cardiorespiratory response and fitness on the treadmill in a 20- to 85-year-old population. Chest 2013; 144: 241-248.

16 Loe H, Rognmo Ø, Saltin B, et al. Aerobic capacity reference data in 3816 healthy men and women 20-90 years. PLoS One 2013; 8: e64319.

17 Koch B, Schäper C, Ittermann T, et al. Reference values for cardiopulmonary exercise testing in healthy volunteers: the SHIP study. Eur Respir J 2009; 33: 389-397.

18 Voorrips LE, Ravelli AC, Dongelmans PC, et al. A physical activity questionnaire for the elderly. Med Sci Sports Exerc 1991; 23: 974-979.

19 Fleg JL, Morrell CH, Bos AG, et al. Accelerated longitudinal decline of aerobic capacity in healthy older adults. Circulation 2005; 112: 674-682.

20 Inbar O, Oren A, Scheinowitz M, et al. Normal cardiopulmonary responses during incremental exercise in 20- to 70-yr-old men. Med Sci Sports Exerc 1994; 26: 538-546.

21 Saengsuwan J, Nef T, Laubacher M, et al. Comparison of peak cardiopulmonary performance parameters on a robotics-assisted tilt table, a cycle and a treadmill. PLoS One 2015; 10: e0122767. 